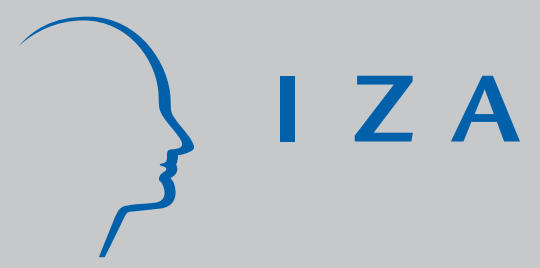

IZA DP No. 264

Return Migration, Wage Differentials, and the Optimal Migration Duration

Christian Dustmann

February 2001 


\title{
Return Migration, Wage Differentials, and the Optimal Migration Duration
}

\author{
Christian Dustmann \\ University College London, CEPR, London and IZA, Bonn
}

Discussion Paper No. 264

February 2001

\author{
IZA \\ P.O. Box 7240 \\ D-53072 Bonn \\ Germany \\ Tel.: $+49-228-3894-0$ \\ Fax: +49-228-3894-210 \\ Email: iza@iza.org
}

This Discussion Paper is issued within the framework of IZA's research area Mobility and Flexibility of Labor Markets. Any opinions expressed here are those of the author(s) and not those of the institute. Research disseminated by IZA may include views on policy, but the institute itself takes no institutional policy positions.

The Institute for the Study of Labor (IZA) in Bonn is a local and virtual international research center and a place of communication between science, politics and business. IZA is an independent, nonprofit limited liability company (Gesellschaft mit beschränkter Haftung) supported by the Deutsche Post AG. The center is associated with the University of Bonn and offers a stimulating research environment through its research networks, research support, and visitors and doctoral programs. IZA engages in (i) original and internationally competitive research in all fields of labor economics, (ii) development of policy concepts, and (iii) dissemination of research results and concepts to the interested public. The current research program deals with (1) mobility and flexibility of labor markets, (2) internationalization of labor markets and European integration, (3) the welfare state and labor markets, (4) labor markets in transition, (5) the future of work, (6) project evaluation and (7) general labor economics.

IZA Discussion Papers often represent preliminary work and are circulated to encourage discussion. Citation of such a paper should account for its provisional character. 
IZA Discussion Paper No. 264

February 2001

\section{ABSTRACT}

\section{Return Migration, Wage Differentials, and the Optimal Migration Duration*}

In simple static models, migration increases with the wage differential between host and home country. In a dynamic framework, and if migrations are temporary, the size of the migrant population in the host country depends also on the migration duration. This paper analyses optimal migration durations in a model which rationalises the decision of the migrant to return to his home country, despite persistently higher wages in the host country. The analysis shows that, if migrations are temporary, the optimal migration duration may decrease if the wage differential grows larger. Using micro data for Germany, the second part of the paper provides some empirical evidence which is compatible with this hypothesis.

JEL Classification: D9, F22

Keywords: Life cycle models, international migration

Christian Dustmann

Department of Economics

University College London

Gower Street

London WC1E 6BT

UK

Tel.: +44 2076795832

Fax: +44 2079162775

Email: c.dustmann@ucl.ac.uk

\footnotetext{
* I would like to thank lan Preston and Frank Windmeijer for thoughtful comments and suggestions.
} 


\section{Introduction}

The wage differential between sending country and receiving country is a core variable for explaining migrations. Static models generally predict that the number of individuals who consider a migration as optimal increases with the wage differential (see, for instance, Sjaastadt (1962) and Harris and Todaro (1970)). As a consequence, these models imply that the migrant population in the host region increases if economic disparity rises. However, predictions of neoclassical static models are often not compatible with empirical evidence. Carrington et al. (1996), for instance, analyse the increase of migrations of southern blacks to the North of the US between 1915 and 1960, which occurred despite a decreasing income differential. They argue that these migrations can be explained within a dynamic model, where moving costs are endogenous.

In this paper, we focus on another aspect of migration which needs a dynamic framework to be appropriately analysed. While in a static world, all migrations are permanent, individuals may also return migrate in a dynamic setting. In this case, the size of the migrant population in the receiving country at any time depends not only on the inflow, but also on the outflow of immigrants. Now the length of migrations becomes an important determinant for the size of the migrant population. Accordingly, to investigate the effect of any parameter, like the wage differential, on the stock of immigrants in the host country at any time requires that one analyses its effect on the migration decision as well as on the migration duration.

To date, much of the economic literature considers migrations as permanent. But temporary migrations are frequent, and often the rule rather than the exception. ${ }^{1}$

\footnotetext{
${ }^{1}$ The large migrations from Southern Europe, North Africa, and Turkey to Central Europe in the
} 
Some authors provide explanations to rationalise the fact that migrants return, despite persistently higher wages in the host country. Stark (1992) uses the theory of relative deprivation and arguments of risk spreading to explain why migrants may return to a less rich economy or region. Hill (1987), Djajic and Milbourne (1988) and Raffelhüschen (1992) explain return migration by allowing for location-specific preferences. Mesnard (2000) investigates the relationship between migration and credit market rationing. She shows that return migration may be one way to overcome capital constraints. Dustmann $(1995,1997)$ shows that further motives for a return migration are a high purchasing power of the host country currency in the migrant's home economy, and higher returns to human capital, accumulated in the host country, in the home economy.

Yet, we know little about the determinants of migrants' duration abroad. Most interesting here is the relationship between the optimal migration duration, and the wage differential between the sending region and the receiving region. Intuition suggests that the optimal duration of the migrant in the host country increases if the wage differential grows larger. The analysis in this paper shows that this is not the case in general. It appears that, while a decrease in the home country wage always increases the optimal migration duration, an increase in the host country wage has an ambiguous effect. As a consequence, migration durations may decrease if the wage differential between home- and host country increases.

One implication of this is that, for a constant inflow of immigrants, the stock of 1950's - 1970's were largely temporary (see Dustmann (1996) for an overview). Temporary migrations are also frequent in Asia (see Pitayanon (1986)), and a considerable percentage of migrations to the US are temporary. Jasso and Rosenzweig (1982), for instance, report that between 20 percent and 50 percent of legal migrants to the US re-emigrated in the 1970's. 
migrants in the host country at any time may decrease if economic disparity rises. Consequences are immediate. More rapid economic growth of immigration countries, relative to bordering emigration regions, may lead to shorter migration cycles and, if immigration is regulated, to a decrease in the migrant population. On the other side, a narrowing of economic differences may have opposite effects. This may lead to unexpected migration outcomes as a reaction to changes in relative economic disparity between countries. For instance, a reduction of economic disparity between East- and West Europe, or Mexico and the US, may lead to longer durations of migrants and, if inflows are regulated, to an increase in the migrant population.

We provide some evidence for the hypothesis that migration durations may decrease if the wage differential increases. Our empirical analysis is based on a panel of immigrants to Germany over a 14 years period. We relate the migration duration of individuals who return back home during that period to a permanent wage measure. We find an inverse U-shaped relationship between completed migration durations and wages, which suggests that durations increase at low levels of host country wages, but decrease at higher levels. In our survey data, we also observe intended migration durations. As a second test for this hypothesis, we relate changes in intentions about the length of the migration period to changes in the wage situation. Again, the evidence we obtain indicates that there is an overall negative relationship between increases in host country wages, and intended migration durations.

The structure of the paper is as follows. Section 2 develops a simple model of return migration, and illustrates that an increase in host country wages may decrease the optimal migration duration. Section 3 provides an empirical analysis of the association between wages in the host country, and the optimal migration duration, and Section 4 
concludes.

\section{Return Migration and Optimal Migration Dura- tion}

We develop the simplest possible model which allows us to illustrate the relationship between wage differentials and optimal migration durations. In our model, time $t$ is continuous. The migrant is offered the option to migrate at $t=0$, and he dies at $t=1$. Should the migrant decide to emigrate, he chooses the optimal duration in the host country jointly with the optimal flows of consumption at home and abroad, $c^{E}$ and $c^{I}$. Wages in home- and host country are denoted by $w^{E}$ and $w^{I}$ respectively, where $w^{I}>w^{E}$ is assumed throughout. Re-migration may occur, despite a persistently more favourable economic condition in the host country, for two reasons: First, a relatively high preference for consumption at home. Secondly, a higher purchasing power of the host country currency at home.

To simplify the analysis, there is no discounting in our model. The migrant's lifetime utility function is given by

$$
J=\hat{t} v\left(\xi^{I}, c^{I}\right)+(1-\hat{t}) v\left(\xi^{E}, c^{E}\right)
$$

where $v\left(\xi^{i}, c^{i}\right), i=E, I$, are the utility functions in home- and host country, which exhibit the properties $v_{c^{i}}>0, v_{c^{i} c^{i}}<0, v_{c^{i} \xi^{i}}>0$, and $\xi^{I}$ and $\xi^{E}$ are preference parameters. The migrant returns at $\hat{t}$. Throughout the analysis, it is assumed that the migrant has a preference for consumption in the home country: $\xi^{I}<\xi^{E}$. 
The migrant maximizes (1) with respect to $c^{E}, c^{I}$, and $t$, subject to the intertemporal budget constraint

$$
\hat{t} w^{I}+(1-\hat{t}) w^{E}-\hat{t} c^{I}-(1-\hat{t}) p c^{E}=0
$$

where the parameter $p$ denotes the price for consumption in the home country, relative to the host country. If $p<1$, consumption abroad is more costly than consumption at home.

Denote the marginal utility of wealth by $\pi$. Differentiating the associated Lagrange problem with respect to the optimal return point $\hat{t}$, and combining terms yields:

$$
\pi\left[\left(w^{I}-w^{E}\right)+\left(p c^{E}-c^{I}\right)\right]-\left[v_{c^{E}}\left(c^{E}, \xi^{E}\right)-v_{c^{I}}\left(c^{I}, \xi^{I}\right)\right]=\Gamma=0 .
$$

Equations (2) and (3) determine, together with the first order conditions for consumption $c^{E}$ and $c^{I}$, the marginal utility of wealth $\pi$ and the optimal point of return $\hat{t}$. Express $\pi, c^{I}$ and $c^{E}$ as a function of $\hat{t}$ using (2) and the first order conditions for $c^{E}$ and $c^{I}$, and substitute into (3). Then (3) is the equilibrium condition which determines the optimal migration duration. The first bracketed term of (3) represents the benefit of remaining an additional unit of time in the host country. It is positive, given our assumptions about preferences, relative prices and wages - each additional unit of time abroad adds to the migrant's lifetime wealth - but decreases in $\hat{t}$. The second term in brackets is the cost of staying a further unit of time abroad. This is the forgone utility, by not being able to consume during that period in the home country. Again, it is positive given our assumptions $\left(\xi^{I}<\xi^{E}\right.$, or $p<1$, or both), and increases in $\hat{t}$. It is easy to show that the difference in benefit and costs decreases in $\hat{t}: \frac{d \Gamma(\hat{t})}{d \hat{t}}<0$. The 
individual returns if the benefit of remaining abroad for an additional unit of time is equal to the costs of doing so.

We consider only the case of an interior solution. Permanent and no migration correspond to the corner solutions of this problem. Migration is permanent if the difference in costs and benefit is positive for $\hat{t} \rightarrow 1$. Migration never occurs if it is negative for $\hat{t} \rightarrow 0$.

Comparative statics with respect to the model parameters are easily derived, using (2), (3), and the first order conditions for $c^{E}$ and $c^{I}$. The change in the optimal migration duration as a reaction to the changes in wages in home- and host country, and other parameters can be summarised by the following equation:

$$
d \hat{t}=\zeta_{1} d w^{E}+\zeta_{2} d w^{I}+\zeta_{3} d z
$$

where $z$ stands for the other model parameters, like the preference parameters and the relative price level. The $\zeta_{i}$ combine the partial derivatives of (2) and (3) with respect to $\pi, \hat{t}, w^{E}$, and $w^{I}$, and the variables in $z$.

Consider first an increase in home country wages $w^{E}$. There is a direct and an indirect effect on $\hat{t}$. The direct effect is a relative wage effect, and it leads to a reduction of the migration duration because the wage differential decreases. The indirect effect is an income effect, and it leads likewise to a reduction of the optimal migration duration. Therefore, $\zeta_{1}<0$, implying that higher home country wages reduce the optimal migration duration.

Now consider an increase in the host country wage $w^{I}$. The relative wage effect leads to an increase in the migration duration, since the wage differential increases. 
However, the income effect is now negative: the value of staying abroad decreases as total lifetime income increases, leading to a reduction in the optimal migration duration. Accordingly, the total effect of an increase in host country wages is ambiguous, and $\zeta_{2} \gtreqless 0 .^{2}$

This simple result has significant implications for evaluating international migrations. It implies that migration durations of migrants from the same origin country may be shorter if they migrate to countries where wages are higher. On the other side, it suggests the possibility that migrants from poorer countries want to remain longer in the host country than migrants from wealthier emigration regions. This may have important consequences for migration policies for both emigration- and immigration countries. In the next section, we explore the empirical implications of our simple model.

\section{Migration Durations and Host Country Wages}

The hypothesis that immigrants reduce their migration duration as a response to higher wages in the host country is, in principle, testable. Ideally, one would like to have data on durations of immigrants from various emigration countries to various immigration countries over the same time period. This would allow one to identify the effect of variations in wages on durations across the immigration countries, keeping variations

\footnotetext{
${ }^{2}$ By total differentiation, one obtains

$$
\zeta_{2}=\frac{-\pi\left[\hat{t}\left(d c^{I} / d \pi\right)+(1-\hat{t}) p\left(d c^{E} / d \pi\right)\right]-\hat{t}\left[\left(w^{I}-w^{E}\right)+\left(p c^{E}-c^{I}\right)\right]}{\left[\left(w^{I}-w^{E}\right)+\left(p c^{E}-c^{I}\right)\right]^{2}}
$$
}

where the first term in the numerator is positive, and the second term is negative. 
due to other origin and destination specific factors constant. Such data is not easily available, however. Hardly ever are migration durations reported.

The approach we follow here is based on a panel of micro data for one country - Germany. We perform two experiments. First, we compute completed migration durations for immigrants who left Germany within our observation window. We explain variations in completed durations across these individuals by variations in host country wages, conditional on a set of individual characteristics, time dummies, and origin country dummies. This approach implies a number of identification issues, which we try to address, as far as our data allows us to. Second, the survey provides us with the intended migration duration of the immigrant in each wave of the panel. We relate changes in these intentions to changes in wages, using within individual wage variations.

We use data from the German Socio-Economic Panel (GSOEP) over a 14 years period. The GSOEP was launched in 1984, and it oversamples immigrants from Southern Europe and Turkey. It is this subsample which we use for our investigation. We concentrate our analysis on males who were older than 18 years at the time of immigration. The reason for this selection is that females and individuals who were younger than 18 are unlikely to have made an independent emigration decision. Immigrations from these countries were predominantly labour migrations, and intended to be temporary by both immigration countries and emigration countries. Aggregate numbers show that a very substantial fraction of these immigrants did in fact return home (see Dustmann (1996) for an overview on labour migration in Europe). 


\section{Completed Durations}

In the GSOEP, the reason for non-response of individuals is reported. The choice of categories includes moved abroad, and we use this information to identify a return migration. Within our observation window of 14 years, we observe 288 cases of return migrations of male immigrants. Table 1 breaks these events down according to the emigration year.

\begin{tabular}{l|ccccccc}
\hline \hline \multicolumn{7}{c}{ Table 1: Summary Statistics, Return Frequencies } \\
\hline Year & 1985 & 1986 & 1987 & 1988 & 1989 & 1990 & 1991 \\
No & 59 & 32 & 29 & 32 & 26 & 14 & 12 \\
Percent & 20.49 & 11.11 & 10.07 & 11.11 & 9.03 & 4.86 & 4.17 \\
\hline Year & 1992 & 1993 & 1994 & 1995 & 1996 & 1997 & Total \\
No & 13 & 16 & 22 & 10 & 15 & 8 & 288 \\
Percent & 4.51 & 5.56 & 7.64 & 3.47 & 5.21 & 2.78 & 100.00 \\
\hline \hline
\end{tabular}

Our first test is to relate these completed migration durations to a measure of the average wage in the host country, controlling for various background characteristics.

Our estimation equation is motivated by equation (4), which linearises the relationship between the optimal migration duration, and the model parameters by total differentiation. The corresponding econometric model is given by:

$$
\tau_{i t}=x_{i t}^{\prime} \beta+\bar{w}_{i}^{E} \gamma^{E}+\bar{w}_{i}^{I} \gamma^{I}+u_{i t},
$$

where $\tau_{i t}$ is the total duration of individual $i$ in the host country who returns in year $t$. In the theoretical model, we have assumed time constant wages in home- and host country. This corresponds to some measure of permanent wages in the empirical 
formulation, which we denote by $\bar{w}_{i}^{E}$ and $\bar{w}_{i}^{I}$. The parameters $\gamma^{E}$ and $\gamma^{I}$ correspond to $\zeta_{1}$ and $\zeta_{2}$, and variables in $x_{i t}$ are individual specific characteristics.

The parameter of interest is $\gamma^{I}$. We do not observe $\bar{w}_{i}^{E}$. We approximate it by the years of schooling obtained before emigration, country of origin dummies, and interaction terms between the two. We report summary statistics on the variables used in this analysis in Table A1 in the appendix.

To construct a measure for $\bar{w}^{I}$, we estimate wage regressions, using the whole sample of immigrants. We then compute wage predictions over the entire period the individual has been in the host country up to the time of the interview, where we include the years before the start of the panel. From these predictions, we compute the average predicted wage for each individual.

Identification is achieved by using information on parental education. We observe in our data the educational achievement of the father and the mother. Parental education is a valid instrument for permanent wages under two conditions. First, it has to explain variation in wages, conditional on the other model regressors. Second, it does not affect the completed migration duration other than through wages, conditional on the individual's education level, and other regressors. Under these assumptions, our estimation strategy avoids possible simultaneity bias, which occurs if, for instance, migrants' accumulation of human capital in the host country depends on the intended total duration abroad. To allow for non-linearities in the response to wages in the immigration country, we use average predicted higher order terms in wages. Additional identification is achieved by interactions of parental education variables with individual's education, age, and country of origin variables. 
Our sample of returning migrants is selected from the overall population of immigrants: We only consider migrants who returned within our 14 years window. Our results are therefore valid only for the selected subsample of returners we use. This should not compromise any qualitative effects of host country wages on migration durations.

We also attempt to control for this selection. This requires additional identification restrictions. Suitable instruments should explain variation in migrants selecting into the sample of returners, conditional on the other model regressors, but should not be correlated with the total migration duration. Such instruments are hard to find. One possible candidate may be the death of the parent, which affects the more fundamental decision whether or not to return rather than the optimal duration, conditional on the return decision. We observe in our data whether the individual's parents (mother or father) are deceased. The reference category are migrants whose parents are still alive, and reside either in Germany, or in the home country. It is likely that parents of migrants who reside in the home country are one reason why the migrant may wish to return. In most Southern European societies and Turkey, caring for the elderly has not yet been institutionalised to the extent it has in some Northern European countries. On the other side, if parents reside (and live) in Germany, then they may have a stronger attachment to the home country, and influence likewise the migrants' return decision.

We estimate models with and without controlling for selection. We model the selection process by estimating a linear probability model, including all immigrants, where the dependent variable is whether the individual returns during the time of the panel. We estimate this equation as a reduced form equation, where we add all regressors, including the death of mother or/and father. We then add the residual to 
(5). ${ }^{3}$ Results on all the auxiliary regressions are given in table A1 in the appendix. The p-values suggest that the set of instruments is significant for each auxiliary equation.

\begin{tabular}{l|cccc}
\hline \hline \multicolumn{5}{c}{ Table 2: Response of Completed Durations } \\
& to Wages & \\
\hline & $\mathbf{1}$ & $\mathbf{2}$ \\
\hline Mean (Predicted Wage) & 2.3839 & 0.4938 & 2.4730 & 0.4964 \\
Mean (Predicted Wage ${ }^{2}$ ) & -0.1321 & 0.0304 & -0.1323 & 0.0321 \\
Mean (Predicted Wage ${ }^{3}$ ) & 0.0012 & 0.0004 & 0.0012 & 0.0005 \\
\hline N.Obs. & \multicolumn{2}{c}{173} & 173 \\
\hline \hline
\end{tabular}

For estimating regressions on the total completed migration duration, our sample of returned migrants reduces to 173 observations, due to missing values in some of the variables (in particular parental background characteristics). ${ }^{4}$ When regressing completed durations on the set of regressors and the average predicted wage, the coefficient on the latter variable is negative, but not significant. To allow for non-linearities in the response of migration duration to wages, we add a third order polynomial in wages. In

${ }^{3}$ This implies the assumption that the mean of the unobservables is related to returning during the observation window as follows:

$$
E\left(u_{i} \mid z_{i}, I_{i}=1\right)=\delta v_{i}
$$

where $I_{i}=1$ represents those who return home, $z_{i}$ includes all regressors, including whether father or mother are deceased, and where $v_{i}=I_{i}-E\left(I_{i} \mid z_{i}\right)$ is the residual from the linear probability model.

${ }^{4}$ To check whether this attrition is selective, we test whether the differences in means of explanatory variables (including age, education, and origin) for the full sample (288 observations), and the final sample used for estimation (173 observations) are equal to zero. We can not reject the null hypothesis for any of the variables at the 1 percent level of significance. 
column 1 of table 2, we report the coefficients for the wage polynomial, not controlling for selection; in column 2, we report results when we add the selection term (see table A2 in the appendix for a full set of results). Both specifications give very similar results. The selection term is negative, but not significantly different from zero. For both specifications, the wage coefficients are jointly significant at the one percent level. We have plotted the corresponding profiles in figure 2. The results indicate that completed durations are first increasing in wages, peak at an average hourly wage of about 12 DM (in 1984 German Marks), and decrease thereafter, indicating that migration durations do in fact respond negatively to higher wages in the host country, except at very low levels of wages.

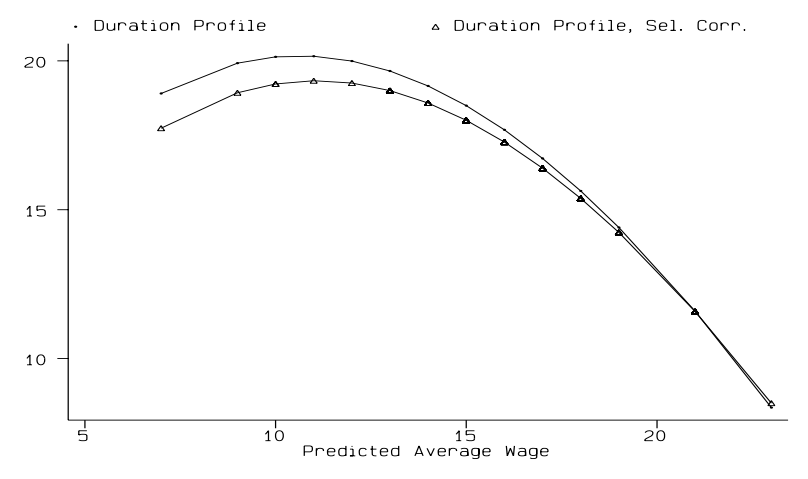

Figure 1: Optimal Migration Duration and Wages

We have performed a number of robustness tests, as far as our data allows us to do. When we restrict our sample to returners only, and use as a measure for $\bar{w}^{I}$ the average wage over the period the migrant is observed in the panel in Germany, the resulting pattern is again inversely U-shaped. When we use parental education as instruments for average wages, this result does not change. 
To check robustness of the results with respect to parental education as instruments for wages, we implement an alternative estimation strategy, where we assume that age does affect the duration equation only linearly, and we use higher order terms in age (as well as interactions with other variables) to identify the model. Identification is weaker in this case, but the set of instruments is significant at the 10 percent level in all first stage regressions. The results we obtain from this specification show a negative relationship between wages and total durations.

\section{Duration Intentions}

A further test for the behavioral implications of our model is to use variations in migrant's return intentions. In the GSOEP, immigrants are asked in each wave about their return intentions. Possible responses are I wish to remain permanently in Germany or I wish to return to my home country. If the individual falls into the second category, he is asked to specify the number of years he intends to remain in Germany. From this information we construct a measure for the number of years in Germany before the individual reaches retirement age (which we set at 64).

Although our theoretical model is deterministic, the behavioral implications are that immigrants may compensate for lower (higher) wages in the host country by increasing (decreasing) their optimal migration duration. Therefore, a decrease (increase) in wages, to the extent that it is not foreseen, should lead to a compensating change in migration durations. A further test for the behavioral implications of the model would be to relate intentions to the migrant's wage situation. The repeated informa-

tion on return intentions allows us to estimate difference models, which eliminate all 
(unobserved) individual specific and time constant factors which may affect duration intentions. To the extent that wages in the home country are perceived as constant between two periods, they are likewise eliminated. Any trend is picked up by time dummies.

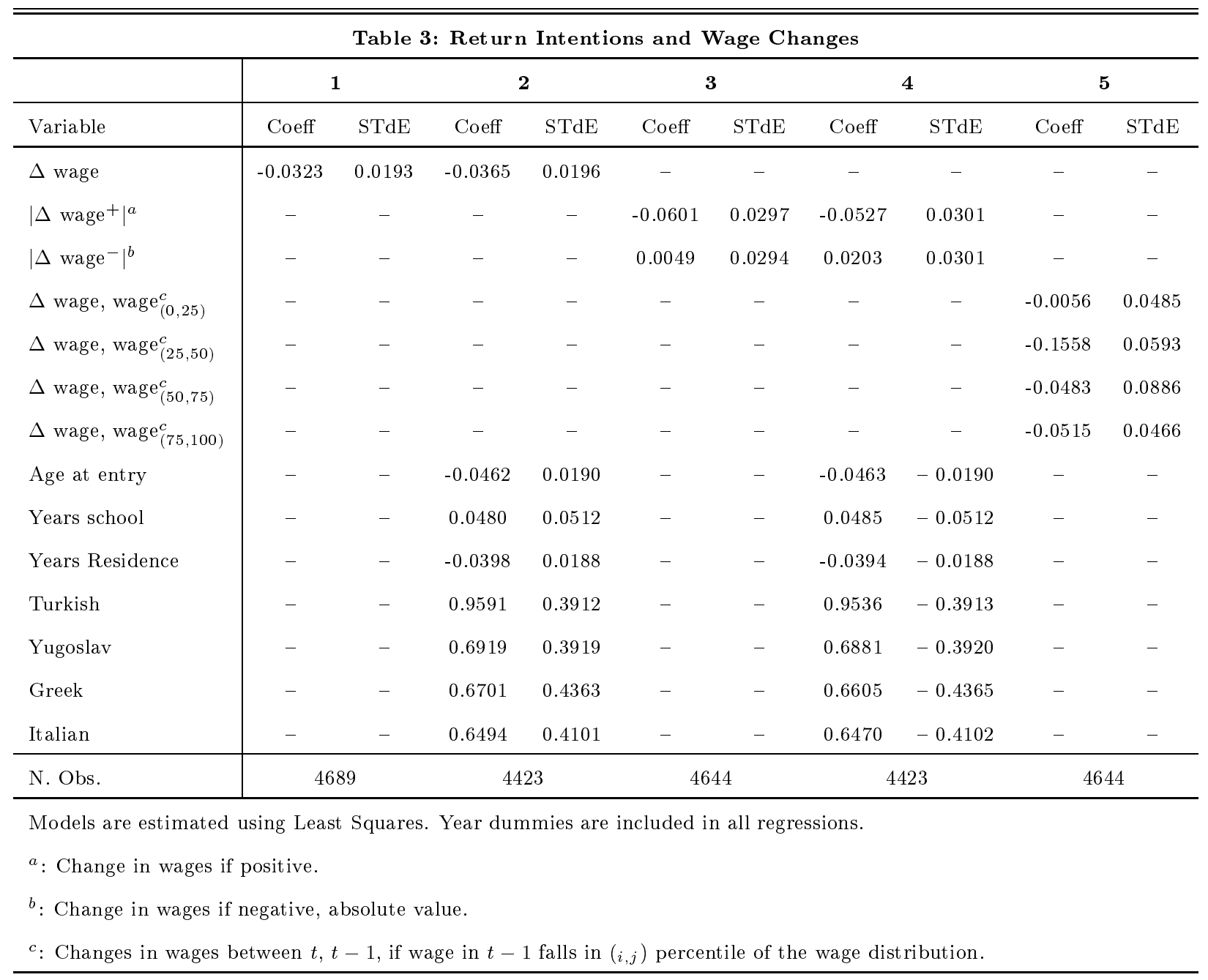

Our dependent variable are changes in return intentions (measured in years) between two subsequent periods. We regress this on changes in wages in two subsequent periods, using Least Squares. If the individual becomes unemployed, we use a replacement ratio of 60 percent of the previous wage for individuals without children, and a 
replacement ratio of 67 percent for individuals with children; this corresponds to the replacement rate of unemployment insurance in Germany. ${ }^{5}$

We report estimation results in Table 3. All regressions include year dummies. In the first column, we regress changes in return intentions on changes in wages. The estimated coefficient suggests that an increase in wages is associated with a decrease in return intentions, and the effect is significant at the 10 percent level. In column 2 , we add other characteristics, like age at entry, years of schooling, years of residence, and origin dummies. Adding these variables does hardly affect the coefficient on the wage variable.

It may well be that the individual reacts differently to an increase, or a decrease in wages. In column 3, we regress again changes in intentions on changes in wages, but we distinguish between an increase, and a decrease, which are both measured in absolute values. The estimated coefficients show that an increase in wages is associated with a decrease in the length of the intended migration period, while a decrease in wages is associated with an increase in the intended migration period. The latter effect is small and not significantly different from zero. In column 4, we add individual characteristics, which has little effect on the wage coefficients.

It is likely that individuals respond differently to wage changes, depending on where they are located in the overall wage distribution. Our estimates in the previous section suggested that the relationship between wages and durations is not monotonic. To investigate this point, we distinguish between wage changes, according to the quartile of

\footnotetext{
${ }^{5}$ We have also estimate models in levels, where we use the same specification than for completed durations, including a third order wage polynomial. The estimated wage response is again inversely U-shaped, with an inflection point at about 19.2 German marks.
} 
the individuals' previous wage in the overall wage distribution. Results are displayed in the last column of table 3 . We find a negative effects of wage changes for individuals in all quartiles of the distribution, with a large and significant effect in the second quartile. Wage responses in the other quartiles are smaller, and not significantly different from zero.

\section{Conclusions}

In this paper, we develop a simple dynamic model where migrants choose their optimal migration duration. The analysis shows that an increase in economic disparity between the sending region and the receiving region may lead to a decrease in the optimal migration duration. A somehow counter-intuitive consequence is that a growing wage differential between the sending and the receiving country may lead to a lower stock of immigrants in the host economy at any point in time, as long as immigration flows are regulated (and vice versa). The intuition behind this result is quite simple: an increase in the host country wage increases the marginal value of staying in the host country (relative wage effect) but, at the same time, decreases the marginal utility of wealth

(income effect). Migrants would, on the one hand, like to prolong their stay abroad as a response to higher wages; on the other hand, the gain from a staying further abroad decreases, and this has a counteracting effect. As a consequence, higher wages abroad may have a positive or a negative effect on the optimal migration duration. Migrants may return earlier, should the wage level in the host country increase.

We provide some tentative evidence for this hypothesis. Using data on total migration durations, we find a non-monotonic and inversely U-shaped relationship between 
wages in the host country, and completed migration durations. We also investigate the response of intended migration durations to wage changes. The repeated information on wages and duration intentions allows us to estimate difference models, which eliminates all time-constant and unobserved components which affect re-migration intentions (as well as time variant factors, as long as their differences are absorbed by time dummies). We find that an increase in wages is associated with a decrease in the intended migration duration.

The empirical evidence we present is compatible with the predictions of our model. It suggests that immigrants may in fact reduce their migration duration as a result of an increase in host country wages. Some of the identification assumptions we have to impose may be debatable, but the evidence seems quite robust. Further research using other data sets should be insightful and interesting.

The analysis has a number of interesting and important implications for migration policies. It adds to results by Carrington et al. (1996) who show that the wage differential as a sole indicator for migration intensity is misleading, since it neglects changes in moving costs. We argue here that the wage differential may also lead to misleading conclusions when used as an indicator for the size of the migrant population in the host region. In fact, our analysis shows increasing disparity may lead to a decreasing migrant population in the host region, if inflows are kept constant. Our results have clear implications for evaluating many migration situations, like EastWest migrations in Europe. They add useful insights when attempting to predict the scope of migration movements within the European union after further enlargements. 


\section{REFERENCES}

Carrington, W.J, E. Detragiache, T. Vishwanath (1996): "Migration with Endogenous Moving Costs," American Economic Review, 86, 909-930.

DjAJic, S., R. Milbourne (1988): “A General Equilibrium Model of Guest-Worker Migration: A Source-Country Perspective," Journal of International Economics, 25, 335-351

Dustmann, C. (1995): "Savings Behavior of Migrant Workers: A Life-Cycle Analysis," Zeitschrift für Wirtschafts- und Sozialwissenschaften115, 511-533.

Dustmann, C. (1997): "Return Migration, Uncertainty and Precautionary Savings," Journal of Development Economics, 52, 295-316.

Dustmann, C. (1996): "Return Migration - The European Experience," Economic Policy, $22,214-250$.

HARRIS, J.R. AND M.P. TODARo (1970): "Migration, Unemployment, and Development: A Two-Sector Analysis," American Economic Review, 70, 126-142.

HiLl, J.K. (1987): "Immigrant Decisions Concerning Duration of Stay and Migration Frequency," Journal of Development Economics, 25, 221-234

JAsso, G. AND M. R. Rosenzweig (1982): "Estimating the Emigration Rates of Legal Immigrants using Administrative and Survey data: The 1971 Cohort of Immigrants to the United States," Demography, 19 ,279-290.

MesnaRD, A. (2000), "Temporary Migration and Capital Market Imperfections", mimeo, University of Toulouse.

Pitayanon, S. (1986): “Asian Workers Abroad," in: Social and Human Sciences in Asia and the Pacific, RUSHSAP Series on Monographs and Occasional Papers 15, Bangkok: Unesco Regional Office 
RAfFelhüschen, B. (1992): "Labor Migration in Europe: Experiences from Germany after Unification," European Economic Review, 36, 1453-1473.

SjaAstad, L.A. (1962): “The Costs and returns of Human Migration," Journal of Political Economy, Supplement, 70.

Stark, O. (1992): The Migration of Labour, Blackwell, Oxford. 


\begin{tabular}{l|lc}
\hline \multicolumn{2}{c}{ Table A1: } & Descriptive Statistics \\
\hline Variable & Mean & StdDev \\
\hline Years of Schooling & 9.898 & 2.124 \\
Age & 46.376 & 9.567 \\
Total Duration & \\
Turkish & 18.748 & 7.686 \\
Yuoslavian & 0.315 & 0.464 \\
Greek & 0.229 & 0.420 \\
Italian & 0.147 & 0.354 \\
Mean Wage & 0.199 & 0.399 \\
Mean Pred. Wage & 17.339 & 5.295 \\
Schooling Mother & 16.320 & 1.574 \\
Schooling Father & 7.990 & 1.677 \\
Father Deceased & 0.508 & 0.974 \\
Mother Deceased & 0.341 & 0.499 \\
\hline \hline
\end{tabular}

$a$ : Only Returners.

${ }^{b}$ : Prediction computed, including pre-survey years. 


\begin{tabular}{|c|c|c|c|c|c|c|c|c|}
\hline \multicolumn{9}{|c|}{ Table A2: Auxiliary Regressions } \\
\hline \multirow[t]{2}{*}{ Variables } & \multicolumn{2}{|c|}{ Wage } & \multicolumn{2}{|c|}{ Wage $^{2}$} & \multicolumn{2}{|c|}{ Wage $^{3}$} & \multicolumn{2}{|c|}{ Return } \\
\hline & Coeff. & StdE & Coeff. & StdE & Coeff. & StdE & Coeff. & StdE \\
\hline Age & 1.6445 & 0.3493 & 43.7854 & 22.7306 & 369.0706 & 1843.627 & 0.0749 & 0.0168 \\
\hline $\mathrm{Age}^{2}$ & -0.0347 & 0.0082 & -0.8645 & 0.5399 & -0.0175 & 43.7920 & -0.0021 & 0.0003 \\
\hline $\mathrm{Age}^{3}$ & 0.0002 & 0.0001 & 0.0044 & 0.0041 & -0.0904 & 0.3387 & 0.0000 & 0.0000002 \\
\hline Years Schooling & -0.1715 & 0.1383 & -6.6634 & 9.0003 & -58.2109 & 729.9978 & 0.0182 & 0.0078 \\
\hline Turkish & -3.4834 & 1.3650 & -164.9174 & 88.8282 & -6606.461 & 7204.65 & 0.2648 & 0.0731 \\
\hline Yugoslavian & -3.2202 & 1.4293 & -133.5283 & 93.0113 & -2192.009 & 7543.934 & 0.0952 & 0.0777 \\
\hline Greek & -4.3192 & 1.5365 & -277.8497 & 99.9828 & -14391.62 & 8109.376 & 0.1220 & 0.0807 \\
\hline Italian & -0.9019 & 1.4568 & -73.6093 & 94.7994 & -4750.919 & 7688.965 & 0.3283 & 0.0804 \\
\hline Yug*Years Schooling & 0.7155 & 0.1150 & 33.4305 & 7.4845 & 1454.872 & 607.0512 & -0.0242 & 0.0066 \\
\hline Tur*Years Schooling & 0.3525 & 0.1131 & 14.4389 & 7.3626 & 454.324 & 597.1653 & -0.0281 & 0.0064 \\
\hline It*Years Schooling & 0.2696 & 0.1213 & 12.0089 & 7.8956 & 477.562 & 640.3981 & -0.0250 & 0.0069 \\
\hline Gr*Years Schooling & 0.9785 & 0.1284 & 49.5750 & 8.3591 & 2130.185 & 677.9912 & -0.0167 & 0.0070 \\
\hline School Father (SchF) & -0.5173 & 0.2561 & -19.5828 & 16.6665 & -439.1758 & 1351.787 & 0.0064 & 0.0138 \\
\hline (Years Schooling)*SchF & -0.0018 & 0.0134 & -0.2101 & 0.8755 & -34.68901 & 71.0146 & 0.0007 & 0.0007 \\
\hline School Mother (SchM) & 0.1759 & 0.0504 & 10.7185 & 3.2823 & 671.3307 & 266.2204 & 0.0018 & 0.0027 \\
\hline Tur*SchF & -0.0107 & 0.1234 & 1.7698 & 8.0312 & 225.2008 & 651.3981 & -0.0195 & 0.0066 \\
\hline It*SchF & -0.2483 & 0.1437 & -6.5152 & 9.3563 & 78.4379 & 758.8691 & -0.0282 & 0.0080 \\
\hline $\mathrm{Gr}^{*} \mathrm{SchF}$ & -0.6341 & 0.1413 & -24.6369 & 9.1948 & -700.5128 & 745.7732 & -0.0017 & 0.0073 \\
\hline Yug*SchF & -0.4385 & 0.1289 & -24.3109 & 8.3925 & -1583.205 & 680.6994 & -0.0066 & 0.0068 \\
\hline Age*SchF & 0.0217 & 0.0039 & 0.8323 & 0.2585 & 26.3691 & 20.9715 & -0.0002 & 0.0002 \\
\hline Mother Deceased & - & - & - & - & - & - & 0.1819 & 0.0489 \\
\hline Father Deceased & - & - & - & - & - & - & -0.2292 & 0.0548 \\
\hline$(\text { M. Deceased })^{*}$ Age & - & - & - & - & - & - & 0.0045 & 0.0011 \\
\hline (F. Deceased $)^{*}$ Age & - & - & - & - & - & - & -0.0035 & 0.0010 \\
\hline Const & -9.2837 & 5.1996 & -445.3408 & 338.3467 & -8607.3322 & 27442.52 & -0.8438 & 0.2627 \\
\hline N.Obs. & \multicolumn{2}{|c|}{6062} & \multicolumn{2}{|c|}{6062} & \multicolumn{2}{|c|}{6062} & \multicolumn{2}{|c|}{8097} \\
\hline $\mathrm{F}\left(n_{1}, n_{2}\right)^{a}$ & \multirow{2}{*}{\multicolumn{2}{|c|}{$\begin{array}{c}\mathrm{F}(8,6030)=13.48 \\
0.00\end{array}$}} & \multirow{2}{*}{\multicolumn{2}{|c|}{$\begin{array}{c}\mathrm{F}(8,6030)=6.41 \\
0.00\end{array}$}} & \multirow{2}{*}{\multicolumn{2}{|c|}{$\begin{array}{c}\mathrm{F}(8,6030)=3.13 \\
0.00\end{array}$}} & \multirow{2}{*}{\multicolumn{2}{|c|}{$\begin{array}{c}\mathrm{F}(4,8061)=7.44 \\
0.00\end{array}$}} \\
\hline P-Value & & & & & & & & \\
\hline
\end{tabular}

Source: GSOEP, waves 1-14

Note: All regressions include time dummies.

${ }^{a}$ : Test for joint significance of instruments. These include schooling father and mother and interactions with individual characteristics in columns 1-3, and dummies whether father/ mother are deceased, and interactions with age in column 4. 


\begin{tabular}{|c|c|c|c|c|}
\hline \multicolumn{5}{|c|}{ Table A3: Full Set of Results } \\
\hline \multirow[t]{2}{*}{ Variables } & \multicolumn{2}{|c|}{1} & \multicolumn{2}{|c|}{2} \\
\hline & Coeff. & StdE & Coeff. & StdE \\
\hline Age & -0.3584 & 1.1036 & -1.7270 & 1.6622 \\
\hline $\mathrm{Age}^{2}$ & 0.0354 & 0.0255 & 0.0706 & 0.0417 \\
\hline $\mathrm{Age}^{3}$ & -0.0003 & 0.0001 & -0.0006 & 0.0003 \\
\hline Years Schooling & -0.3158 & 0.3278 & -0.6219 & 0.4322 \\
\hline Turkish & -15.5010 & 4.1371 & -16.4836 & 4.2462 \\
\hline Yugoslavian & -15.9094 & 5.0475 & -15.7915 & 4.9231 \\
\hline Greek & -11.6906 & 5.9673 & -12.8980 & 6.0866 \\
\hline Italian & -3.2627 & 4.3440 & -6.2131 & 5.4927 \\
\hline Yug*Years Schooling & 1.2393 & 0.4332 & 1.5190 & 0.5159 \\
\hline Tur*Years Schooling & 1.3186 & 0.5032 & 1.5408 & 0.5621 \\
\hline It*Years Schooling & 0.2107 & 0.4317 & 0.6615 & 0.6497 \\
\hline Gr*Years Schooling & 1.0195 & 0.6011 & 1.2122 & 0.6409 \\
\hline Mean (Pred. Wage) & 2.3839 & 0.4938 & 2.4730 & 0.4964 \\
\hline Mean (Pred. Wage ${ }^{2}$ ) & -0.1321 & 0.0304 & -0.1323 & 0.0321 \\
\hline Mean (Pred. Wage ${ }^{3}$ ) & 0.0012 & 0.0004 & 0.0012 & 0.0005 \\
\hline Residual (Return) & & & -11.0358 & 10.6675 \\
\hline Constant & -13.8676 & 13.6645 & 12.7892 & 28.3707 \\
\hline N.Obs. & \multicolumn{2}{|c|}{173} & \multicolumn{2}{|c|}{173} \\
\hline $\mathrm{F}\left(n_{1}, n_{2}\right)^{a}$ & \multirow{2}{*}{\multicolumn{2}{|c|}{$\mathrm{F}(3,146)=10.57$}} & \multirow{2}{*}{\multicolumn{2}{|c|}{$\begin{array}{c}\mathrm{F}(3,146)=9.34 \\
0.00\end{array}$}} \\
\hline P-Value & & & & \\
\hline
\end{tabular}

Source: GSOEP, waves 1-14

Note: All regressions include time dummies.

${ }^{a}$ : Test for joint significance of wage variables. 


\section{IZA Discussion Papers}

\section{No Author(s)}

181

E. Wasmer

Y. Zenou

182 M. Fertig

C. M. Schmidt

183 M. Fertig

C. M. Schmidt

184 M. Corak

B. Gustafsson

T. Österberg

185 H. Bonin

K. F. Zimmermann

186

C. Dustmann

187
T. K. Bauer
M. Lofstrom
K. F. Zimmermann

188
A. Kapteyn
A. S. Kalwij
A. Zaidi

189

W. Arulampalam

190

C. Dustmann

I. Preston

191

192

G. C. Giannelli

C. Monfardini

193 A. Kunze

F. Pastore

G. Brunello

F. Büchel

A. Mertens

Titel

Area

Date

Space, Search and Efficiency

2

$8 / 00$

Discretionary Measures of Active Labor Market Policy: The German Employment Promotion Reform in Perspective

Aggregate-Level Migration Studies as a Tool for 1 Forecasting Future Migration Streams

Intergenerational Influences on the Receipt of 3 Unemployment Insurance in Canada and Sweden

The Post-Unification German Labor Market

4

$8 / 00$

Temporary Migration and Economic Assimilation

$8 / 00$

Immigration Policy, Assimilation of Immigrants and Natives' Sentiments towards Immigrants: Evidence from 12 OECD-Countries

The Myth of Worksharing

5

$8 / 00$

Is Unemployment Really Scarring? Effects of

3

$8 / 00$

Unemployment Experiences on Wages

Racial and Economic Factors in Attitudes to

Immigration

$8 / 00$

Joint Decisions on Household Membership and Human Capital Accumulation of Youths: The role of expected earnings and local markets

$8 / 00$

Absolute Risk Aversion and the Returns to

5

$8 / 00$ Education

The Determination of Wages and the Gender Wage Gap: A Survey

Restructuring in Poland

Overeducation, Undereducation, and the Theory of Career Mobility 
198 M. Kreyenfeld

A Forgotten Issue: Distributional Effects of Day 
212 X. Gong

A. van Soest

P. Zhang

213 X. Gong

A. van Soest

E. Villagomez

214 X. Gong

A. van Soest

215 J. Ermisch

M. Francesconi

216 F. Büchel

217

J. Hansen

R. Wahlberg

218 C. Dustmann

A. van Soest

219 F. Kramarz

T. Philippon

220 W. A. Cornelius

E. A. Marcelli

221

C. Grund

222 W.P.M. Vijverberg

223 M. Rosholm

M. Svarer

J. Schwarze

225

L. Modesto

J. P. Thomas
Sexual Bias and Household Consumption: A

Mobility in the Urban Labor Market: A Panel Data 1

The Effect of Parents' Employment on Children's

The Effects of Overeducation on Productivity in Variables

The Impact of Differential Payroll Tax Subsidies on 5 Minimum Wage Employment United States: New Evidence from California and Mexico

Wages as Risk Compensation in Germany 

former Soviet Union to Israel: Who is coming when?

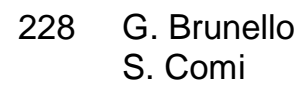

C. Lucifora

229 R. Coimbra

T. Lloyd-Braga

L. Modesto

230 L. Modesto

231

G. Saint-Paul

232

E. Bardasi

M. Francesconi

233

C. Dustmann

C. M. Schmidt

234

R. Rotte

M. Steininger

235

W. Schnedler

236
R. Hujer
M. Caliendo

237 S. Klasen

I. Woolard

238 R. Euwals

A. Börsch-Supan

A. Eymann

239 F. Andersson

K. A. Konrad

240

W. Koeniger
The College Wage Gap in 10 European and Earnings: An Empirical Study for Portugal Wahlerfolge in Deutschland: Das Beispiel der Europawahlen 1994 und 1999

Who gets the Reward? An Empirical Exploration of Bonus Pay and Task Characteristics

Evaluation of Active Labour Market Policy: 

Soviet Union: A Study of the Suicide Epidemic in the 1990s

244 S. M. Fuess, Jr. M. Millea

T. J. Hatton

J. G. Williamson

251

R. Yemtsov

252

R. Yemtsov

254 H. Gersbach

A. Schniewind

255 H. Gersbach

A. Schniewind

T. Boeri

H. Brücker

Pay and Productivity in a Corporatist Economy:

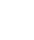


258 M. Rosholm

The Times They Are A-Changin':

K. Scott

Organizational Change and Immigrant

L. Husted

Employment Opportunities in Scandinavia

259 A. Ferrer-i-Carbonell

Poverty in the Russian Federation

4

02/01

B. M.S. van Praag

260

P. Cahuc

F. Postel-Vinay

Temporary Jobs, Employment Protection and

$1 / 3$

$02 / 01$

Labor Market Performance

261 M. Lindahl

Home versus School Learning:

5

$02 / 01$

A New Approach to Estimating the Effect of Class

Size on Achievement

262 M. Lindahl

Summer Learning and the Effect of Schooling:

5

$02 / 01$

Evidence from Sweden

263 N. Datta Gupta

Children and Career Interruptions:

5

$02 / 01$

N. Smith

The Family Gap in Denmark

264

C. Dustmann

Return Migration, Wage Differentials, and the

1

$02 / 01$ Optimal Migration Duration 